\title{
Survival of chronic hemodialysis patients over 80 years of age
}

This article was published in the following Dove Press journal:

Clinical Interventions in Aging

16 April 2014

Number of times this article has been viewed

\section{Branka Sladoje-Martinovic Ivana Mikolasevic \\ Ivan Bubic \\ Sanjin Racki \\ Lidija Orlic}

Department of Nephrology and Dialysis, Division of Internal Medicine, University Hospital Center Rijeka, Rijeka, Croatia
Correspondence: Lidija Orlic Department of Nephrology and Dialysis, University Hospital Center Rijeka, Tome Strižića 3, 51000 , Rijeka, Croatia

Tel +385 5I 407487

Fax +385 5। 407 I56

Email lidija.orlic@ri.t-com.hr
Background/aim: The number of elderly patients with chronic kidney disease (CKD) stage 5 management with hemodialysis (HD) is steadily increasing. Therefore we analyzed the number of new CKD patients $\geq 80$ years managed with HD and their survival through the study period. We aimed also, to identify which of several key variables might be independently associated with survival in this very elderly population of patients.

Patients and methods: This was a single-center, retrospective cohort study that took place during the period from January 1987 to September 2012. The study consisted of 78 (50 male and 28 women) very elderly patients ( $\geq 80$ years of age); the mean age at which HD was initiated was $83.2 \pm 2.5$ years. Survival and factors associated with mortality were studied. Survival was defined as the time from start of HD treatment to death (or end of study, if still alive).

Results: In the period from 1987 to 2002 , patients $\geq 80$ years of age were only sporadically treated with HD, but since 2003, the number of new patients has been steadily increasing. The mean survival for our group of patients was $25.1 \pm 22.4$ months (range 1-115 months). Furthermore, 30.8\% patients survived $<12$ months, $29.5 \%$ patients survived $12-24$ months, $30.8 \%$ patients survived 24-60 months, and 9\% patients survived $>60$ months on HD treatment. Older patients were less likely to have diabetes, and primary renal disease did not influence survival. Patients with high C-reactive protein levels and poor nutritional status, as well as those who did not have pre-HD nephrology care and those that had a catheter as vascular access for HD had poor survival. In about half of our patients, the cause of death was cardiovascular disease.

Conclusion: Among patients who were $\geq 80$ years of age at the start of HD treatment, those who received pre-HD nephrology care that followed a planned management pathway, those who had a good nutritional status, and those with an arteriovenous fistula as vascular access for HD at the time of HD initiation had a better survival.

Keywords: chronic kidney disease, elderly patients, pre-HD nephrology care, nutritional status, arteriovenous fistula

\section{Introduction}

Today, the term elderly refers to people who are 65 years of age or older, and in most Western European countries, the proportion of elderly people reaches $14 \%-16 \%$ of population; during 2001, about $15.7 \%$ of the Croatian population was 65 years of age or older. ${ }^{1}$ Furthermore, the number of elderly patients is progressively increasing, and among them are many people that are $\geq 75$ years of age. When hemodialysis (HD) was launched worldwide, elderly patients were often excluded from renal replacement therapy (RRT) because the availability of HD was limited, due to technical and economic reasons. But during the last decade, this changed dramatically, and treatment of the elderly with HD increased with technological development. 
The number of elderly patients with chronic kidney disease (CKD) as well as those with end-stage renal disease (ESRD) is on the rise worldwide. Old age is no longer seen as a contraindication to RRT. In the past decade, in most regions of the world, an increasing number of adults aged 65 years or more were started on RRT each year. Those aged 75 years or more represent the fastest growing segment of the population starting HD. As a consequence of the aging of the HD population, new issues have emerged..$^{2-7}$ Therefore, HD of elderly patients has become routine. For example, in France, 37.9\% of patients who started HD in 2009 were older than 75 years. ${ }^{8}$

HD is a costly but lifesaving therapy offered to patients with ESRD. It is important to consider whether or not age alone can be considered an ethically acceptable criterion for access to HD. Quality of life is an important issue for all HD patients, including the elderly. The physician must weigh the need for HD in relation to life expectancy, complications of the primary disease, or comorbid conditions. However, HD in older adults remains a challenge and raises ethical and socioeconomic concerns. ${ }^{2-5}$

According to these observations, the aims of this study were to analyze the number of new CKD patients $\geq 80$ years of age that were managed with HD and their survival through the study period. Also, the aim was to identify which of several key variables might be independently associated with survival in this very elderly population of patients.

\section{Patients and methods}

Using a single-center, retrospective cohort study design (involving data collected prospectively for a purpose not directly related to the current study), we followed the progress of 78 patients that were $\geq 80$ years of age who initiated chronic HD during the period from January 1987 to September 2012. This included both patients who had been referred to a nephrologist and started HD in a planned manner and those who started HD as an emergency. Patients with evidence of acute kidney injury and those with evidence of advanced progressive metastatic cancer were excluded.

All patients were treated with HD. HD is standard RRT in elderly patients ( $\geq 80$ years) with ESRD at our institution. All of them were dialyzed for 4 hours, three times a week, on polysulfone membranes.

Data on patient demographic characteristics, medical history, and laboratory data were obtained by medical record. Comorbid conditions included the presence of diabetes mellitus, dyslipidemia, and arterial hypertension, as well as obesity. This data was obtained by using a standard questionnaire. The body mass index (BMI) was calculated as weight $(\mathrm{kg})$ divided by height $(\mathrm{m})$ squared. Obesity was defined as a BMI of $>23 \mathrm{~kg} / \mathrm{m}^{2}$. Diabetes mellitus was defined by fasting glucose $\geq 5.6 \mathrm{mmol} / \mathrm{L}$ or drug treatment, and dyslipidemia by triglycerides $\geq 1.7 \mathrm{mmol} / \mathrm{L}$ or by drug treatment or high-density lipoprotein $<1 \mathrm{mmol} / \mathrm{L}$ in men and $<1.29$ in women. Blood pressure was measured with a standard mercury sphygmomanometer. The criterion used for defining arterial hypertension was systolic blood pressure (SP) $>140 \mathrm{mmHg}$ and diastolic pressure (DP) $>90 \mathrm{mmHg}$, or the routine use of antihypertension therapy. The SP and DP values obtained before starting regular HD treatment were taken into account for this study.

We grouped patients into four classes of primary kidney disease: diabetes mellitus, renal vascular disease, chronic pyelonephritis, and other kidney disease. Other kidney diseases consisted of glomerulonephritis and polycystic kidney disease. Renal vascular disease was defined as the presence of long-term arterial hypertension, presence of left-ventricular hypertrophy, hypertensive retinopathy, presence of proteinuria, and gradual deterioration of kidney function. Data on vascular access were collected at 1 month after the start of HD. Pre-HD nephrology care was defined as a referral to a nephrologist for at least 6 months before initiation of HD to provide patients with adequate medical preparation. Catheters included both tunneled and nontunneled catheters (jugular and femoral). Arteriovenous accesses included native fistulas.

Laboratory data included hemoglobin, albumin, and C-reactive protein (CRP) levels and were recorded at the time of HD initiation. BMI was calculated.

All patients were followed for a minimum of 1 year or until death.

The primary endpoint of this study was to determine the number of new patients that were aged 80 or over and their survival through study period. The second endpoint of this analysis was patient survival in relation to sex, primary renal disease, pre-HD care, vascular access, nutritional status, and CRP levels, SP and DP values; as well as the cause of death. For the purpose of this analysis, we classified causes of death as cardiovascular, infection-related, malignant, and other mortality. We analyzed the overall survival of patients according to sex and pre-HD nephrology care. Furthermore, we analyzed the overall survival of patients who had a catheter compared with survival of patients with an arteriovenous fistula as vascular access for HD.

Also, we compared survival of patients divided into subgroups with respect to primary renal disease and three important parameters - nutritional status, inflammatory state, and blood pressure. Poor nutritional status was defined as 
BMI values of less than $23 \mathrm{mg} / \mathrm{kg}^{2}$ and serum albumin levels of less than $40 \mathrm{~g} / \mathrm{L}$.

Survival was defined as the time from starting HD treatment to death (or end of study, if still alive).

\section{Statistical analysis}

Statistical analysis of data was performed using descriptive statistics (mean and standard deviation). Categorical variables were tested by chi-square test. The difference in survival of patients was analyzed with the Kaplan-Meyers method of estimating mortality risk. Univariate and multivariate analyses were assessed using the Cox regression analysis. A $P$-value $<0.05$ was considered to be statistically significant. Statistical analysis was done using MedCalc, version 10 statistical software package (MedCalc Software bvba, Mariakerke, Belgium).

\section{Results}

Table 1 provides a description of the demographic characteristic in the analyzed patients. Of 78 patients with mean

Table I Baseline characteristics

\begin{tabular}{|c|c|}
\hline Mean age (years) & $83.2 \pm 2.5$ (range 80-90) \\
\hline Men, n (\%) & $50(64.1)$ \\
\hline Women, n (\%) & $28(35.9)$ \\
\hline \multicolumn{2}{|l|}{ Comorbid illness } \\
\hline Arterial hypertension, $\mathrm{n}(\%)$ & $55(70.5)$ \\
\hline Diabetes mellitus, n (\%) & $19(24.4)$ \\
\hline Dyslipidemia, n (\%) & $27(34.6)$ \\
\hline \multicolumn{2}{|l|}{ Primary kidney disease } \\
\hline Diabetes mellitus, $\mathrm{n}(\%)$ & $17(2 \mid .8)$ \\
\hline Renal vascular disease, $\mathrm{n}(\%)$ & $32(4 \mid \%)$ \\
\hline Chronic pyelonephritis, n (\%) & $7(9)$ \\
\hline Other, n (\%) & $6(7.7)$ \\
\hline Unknown, n (\%) & $16(20.5)$ \\
\hline Predialysis nephrology care, n (\%) & $40(5 \mid .3)$ \\
\hline \multicolumn{2}{|l|}{ Vascular accesses } \\
\hline Central venous catheter & $40(51.3)$ \\
\hline Arteriovenous fistula & $38(48.7)$ \\
\hline \multicolumn{2}{|l|}{ Therapy } \\
\hline ACE-I/ARB, n (\%) & $35(44.9)$ \\
\hline $\mathrm{CCB}, \mathrm{n}(\%)$ & 60 (76.9) \\
\hline $\mathrm{BB}, \mathrm{n}(\%)$ & $30(38.5)$ \\
\hline Diuretics, n (\%) & $32(4 I)$ \\
\hline Statins, n (\%) & $25(38.5)$ \\
\hline Hemoglobin (g/L) & $93.7 \pm I \mid($ range 68-|3I) \\
\hline Serum albumin $(g / L)$ & $35.3 \pm 4.1$ (range 25-46.5) \\
\hline BMI $\left(\mathrm{kg} / \mathrm{m}^{2}\right)$ & $24.2 \pm 1.7$ (range 16-32) \\
\hline CRP (mg/L) & $48.1 \pm 46.7$ (range $0-113)$ \\
\hline $\mathrm{HbA}_{\mathrm{Ic}}>7 \%, \mathrm{n}(\%)$ & $7(4 \mid .2)$ \\
\hline
\end{tabular}

Note: $\mathrm{N}=78$.

Abbreviations: $A C E-I$, angiotensin-converting enzyme inhibitor; $A R B$, angiotensin receptor blockers; $\mathrm{BB}$, beta blocker; $\mathrm{BMI}$, body mass index; $\mathrm{CCB}$, calcium channel blocker; CRP, C-reactive protein; $\mathrm{HbA}_{\mathrm{Ic}}$, glycated hemoglobin. age $83.2 \pm 2.5$ (range $80-90$ ) years there were $50(64.1 \%)$ male and $28(35.9 \%)$ women $(P=0.001)$. The most common etiology of CKD was renal vascular disease (32 patients), followed by diabetic nephropathy (17 patients). Forty (51.3\%) patients had central venous catheter, and 38 (48.7\%) patients had arteriovenous fistula as the vascular access for HD. Of 78 patients, $40(51.3 \%)$ patients were referred to nephrologists for at least 6 months before initiation of HD.

HD was launched in Croatia in 1966. In our HD center, there were no patients older than 80 years undergoing HD before 1987. In the period from 1987-2002, patients that were $\geq 80$ years of age were only sporadically treated with HD. Since 2003, the number of patients older than 80 years undergoing HD has been steadily increasing (Figure 1).

The mean survival for our group of patients was $25.1 \pm 22.4$ months (range 1-115 months). Furthermore, $24(30.8 \%)$ patients survived less than 12 months, while $23(29.5 \%)$ patients survived 12-24 months on HD treatment. On the other hand, $24(30.8 \%)$ patients survived 24-60 months, and seven ( $9 \%$ ) patients survived more than 60 months on HD treatment.

As shown in Figure 2, there was no statistically significant difference in survival rate between male and female patients $(P=0.486)$.

We were interested to explore whether primary kidney disease and pre-HD nephrology care had an influence on the survival of our elderly patients. Analyzing the survival according to the primary kidney disease, we did not find any statistically significant difference between the four groups of patients (Figure 3 ).

About a half of our patients attended pre-HD nephrology care. Figure 4 shows the Kaplan-Meier curve for survival according to the pre-HD nephrology care. As compared with patients who didn't attend pre-HD nephrology care, patients referred to a nephrologist at least 6 months before initiation of HD had statistically significant better survival $(P<0.0001)$.

In the next step, we investigated the association among vascular access and mortality risk. Elderly patients who had a catheter as vascular access for HD had a 2.5 higher risk for death than did those patients who had arteriovenous fistula (hazard ratio [HR] 2.5286; 95\% confidence interval: 1.5160-4.2116) (Figure 5).

Next we investigated nutritional status, based on serum albumin levels and BMI, and its influence on mortality rate. We have found that a great proportion of our patients had serum albumin levels less than $40 \mathrm{~g} / \mathrm{L}$. The mortality rate was statistically significantly higher for patients with low serum albumin levels and low BMI values (Figures 6 and 7). 


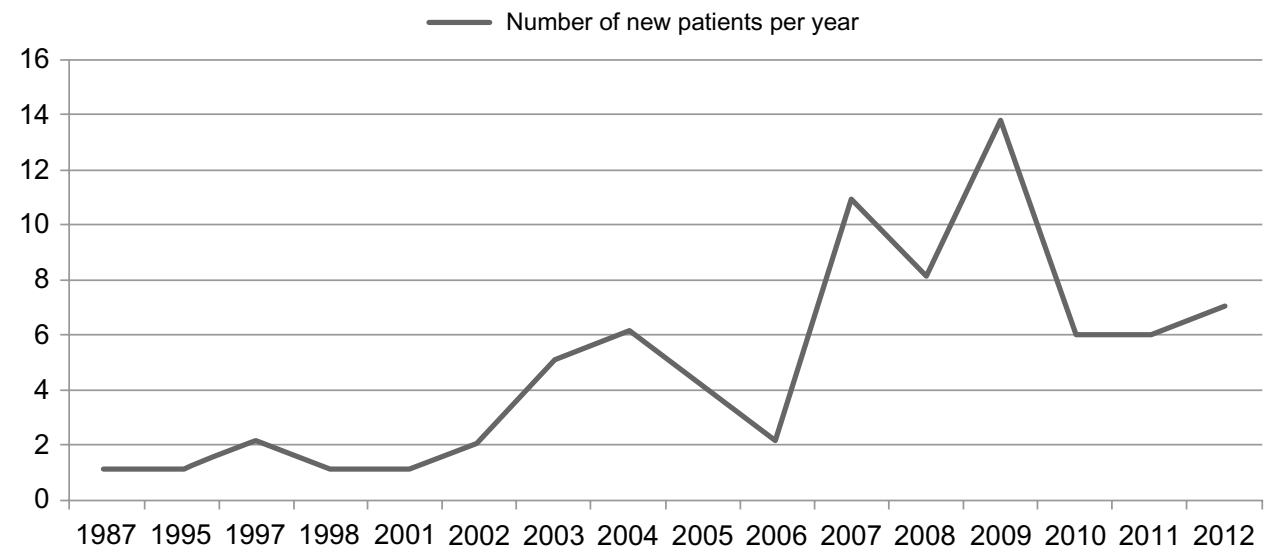

Figure I Number of incident patients that were $\geq 80$ years of age undergoing hemodialysis through the observed period.

Furthermore, we investigated inflammatory state, based on serum CRP levels. According to our results, patients who had CRP levels $>5 \mathrm{mg} / \mathrm{L}$ had a 3.4 higher risk for death than did those patients who had CRP levels $<5 \mathrm{mg} / \mathrm{L}$ (HR 3.3404; 95\% confidence interval: 2.0340-5.6969) (Figure 8).

Finally, we were interested to explore whether SP and DP values had influence on survival of our elderly patients. Analyzing the survival according to the SP and DP values, we did not find any statistically significant difference between the four groups of patients (Figure 9A and B).

Furthermore, univariate analysis of the laboratory tests and clinical features indicated that the serum albumin and CRP levels, BMI values, vascular access and pre-HD care were the predictors of mortality. In contrast, low serum albumin levels $(P<0.0001)$, high CRP values $(P<0.0001)$,

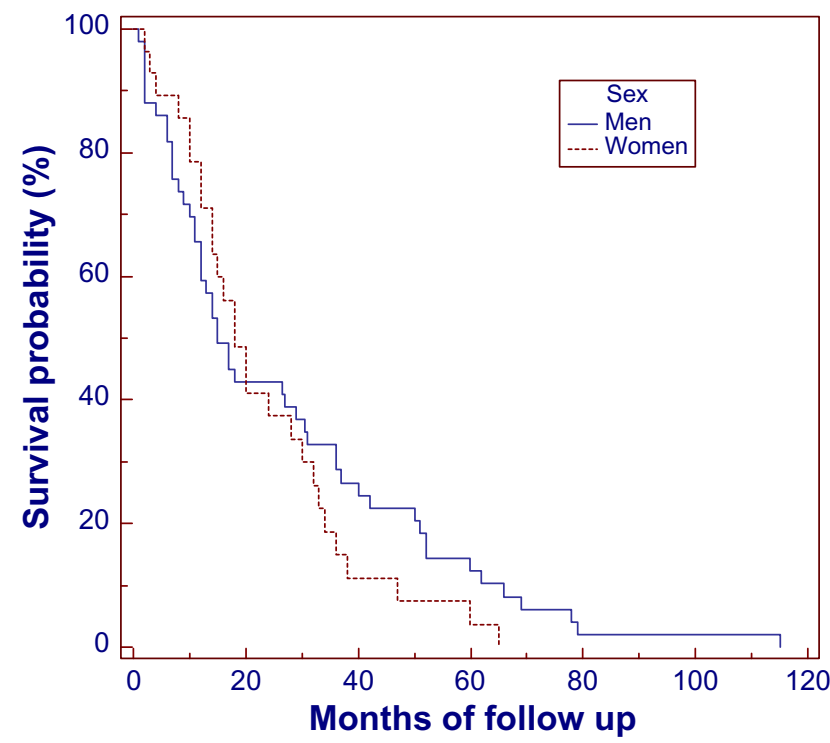

Figure 2 Kaplan-Meier survival curves in elderly hemodialysis patients, according to sex.

Notes: Men, $n=50$; women, $n=28$. catheter use instead of arteriovenous fistula as the vascular access for HD $(P=0.001)$, and absence of pre-HD care $(P=0.02)$ were independent predictors of mortality in the multivariable model.

Analyzing the causes of death in our group of patients, we found that $50 \%$ of patients died as a consequence of cardiovascular disease. The next most common cause of death was infection-related ( $28 \%$ of patients) (Figure 10$)$.

\section{Discussion}

When HD was initiated worldwide, patients of advanced age were often excluded. However, this has changed dramatically during the last decade. This study showed that the number of patients $\geq 80$ years of age starting HD increased over time. Namely, during the 1980s and 1990s, patients that were $\geq 80$ years of

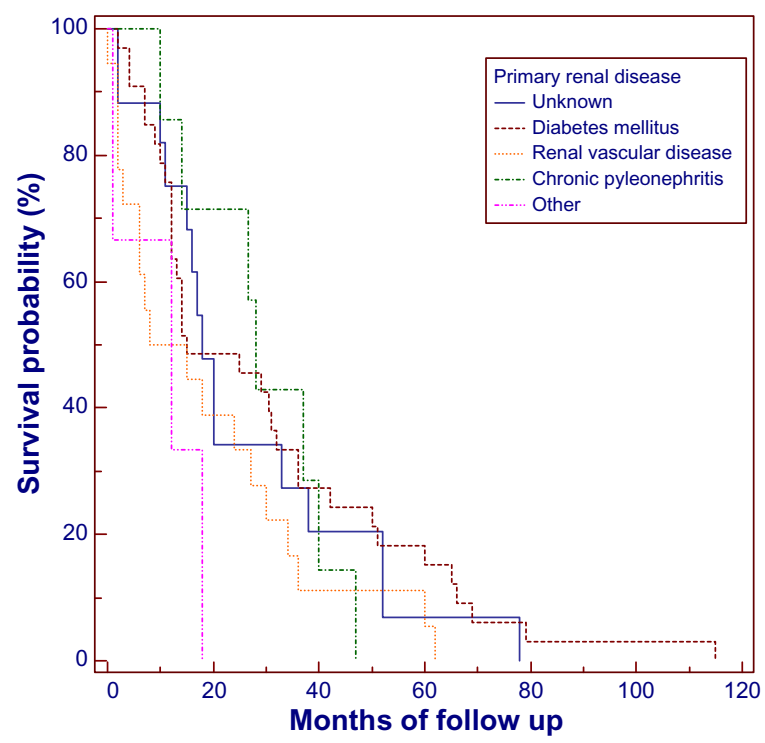

Figure 3 Kaplan-Meier survival curves for elderly hemodialysis patients, according to the primary renal disease.

Note: $P=$ non-significant. 


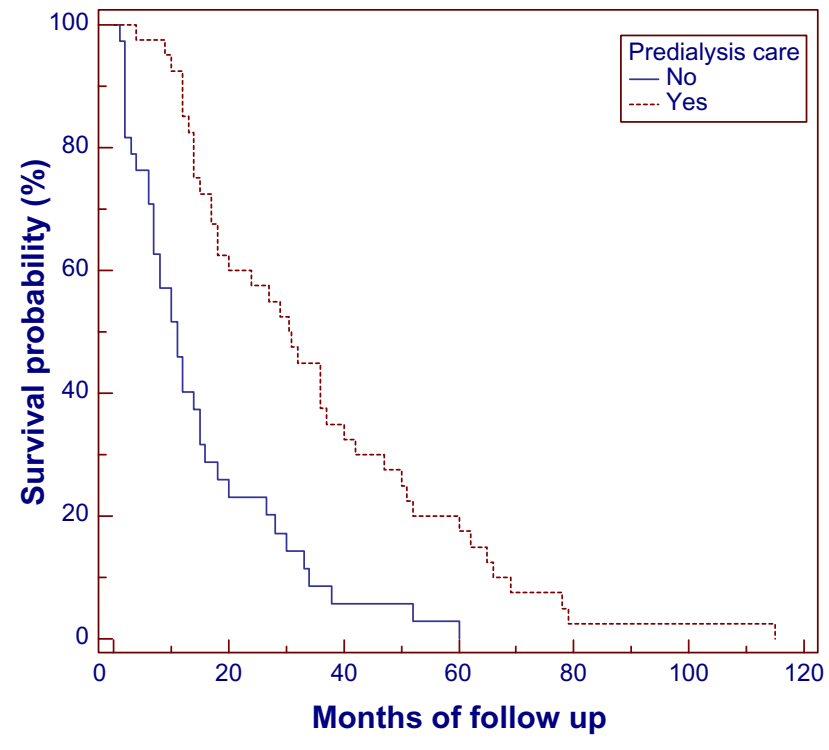

Figure 4 Kaplan-Meier survival curves for elderly hemodialysis patients, according to their predialysis care.

Notes: Patients with no predialysis care, $n=38$; patients with predialysis care, $n=40$. HR 2.5286; 95\% Cl: I.5।60-4.2II6; $P<0.0001$.

Abbreviations: $\mathrm{Cl}$, confidence interval; $\mathrm{HR}$, hazard ratio.

age were only sporadically treated with HD in our institution. On the other hand, since 2003 the number of patients $\geq 80$ years of age treated with HD has been increasing. Our results are in accordance with those in other studies. ${ }^{2-9}$ This can be explained by increased longevity, coupled with technical

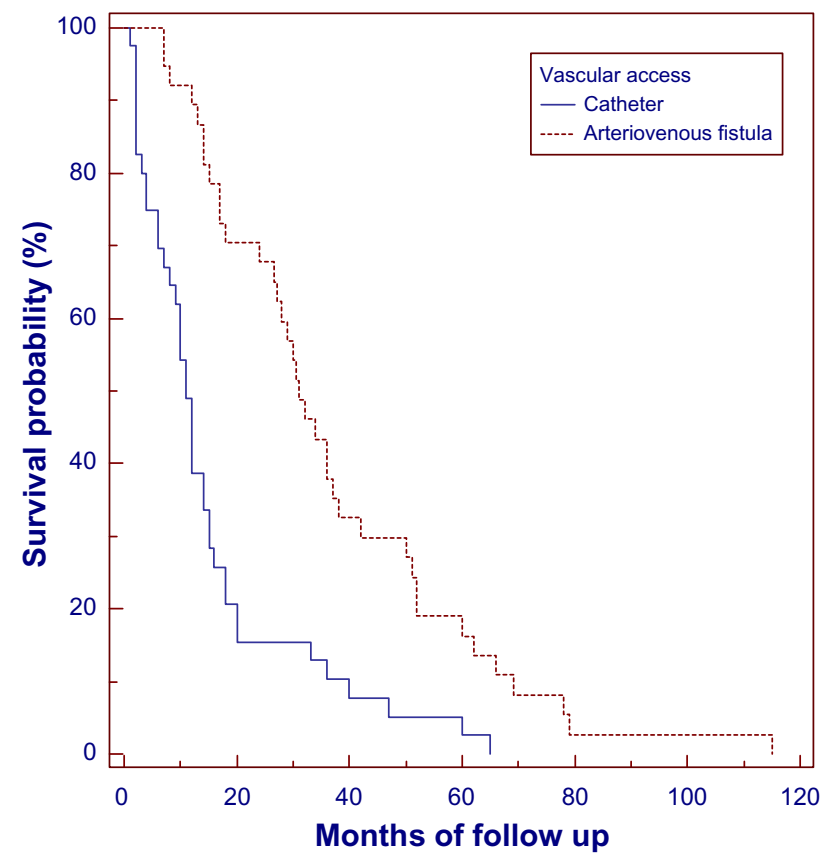

Figure 5 Kaplan-Meier survival curves for arteriovenous fistula versus catheter in elderly hemodialysis patients.

Notes: Catheter vascular access, $n=40$; arteriovenous fistula, $n=38$. HR 2.5। 87; $95 \%$ Cl: I.5384-4. I237; $P<0.000$ I.

Abbreviations: $\mathrm{Cl}$, confidence interval; $\mathrm{HR}$, hazard ratio.

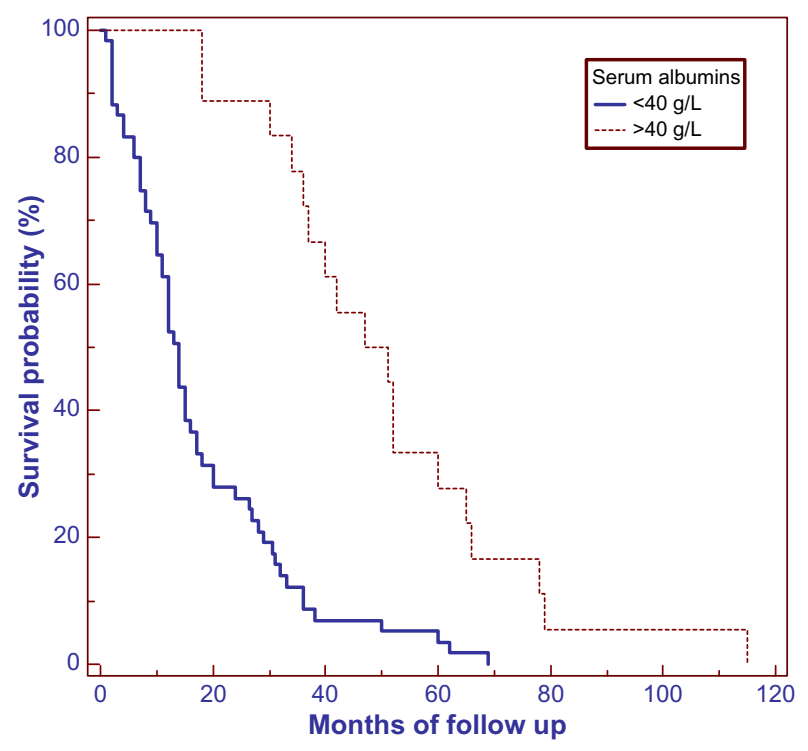

Figure 6 Kaplan-Meier survival curves for elderly hemodialysis patients, according to the serum albumin levels.

Notes: Serum albumin $<40 \mathrm{~g} / \mathrm{L}, \mathrm{n}=60$; serum albumin $>40 \mathrm{~g} / \mathrm{L}, \mathrm{n}=18$. HR 3.0850; 95\% Cl: I.9676-4.837I; $P<0.000$ I.

Abbreviations: $\mathrm{Cl}$, confidence interval; $\mathrm{HR}$, hazard ratio.

advances and heightened public expectation that has contributed to an unprecedented increase in demand for HD therapies in the older age group. Therefore, elderly patients account for an increasing fraction of patients on RRT worldwide, reaching $25 \%$ to $30 \%$ in most ESRD registries. During the last

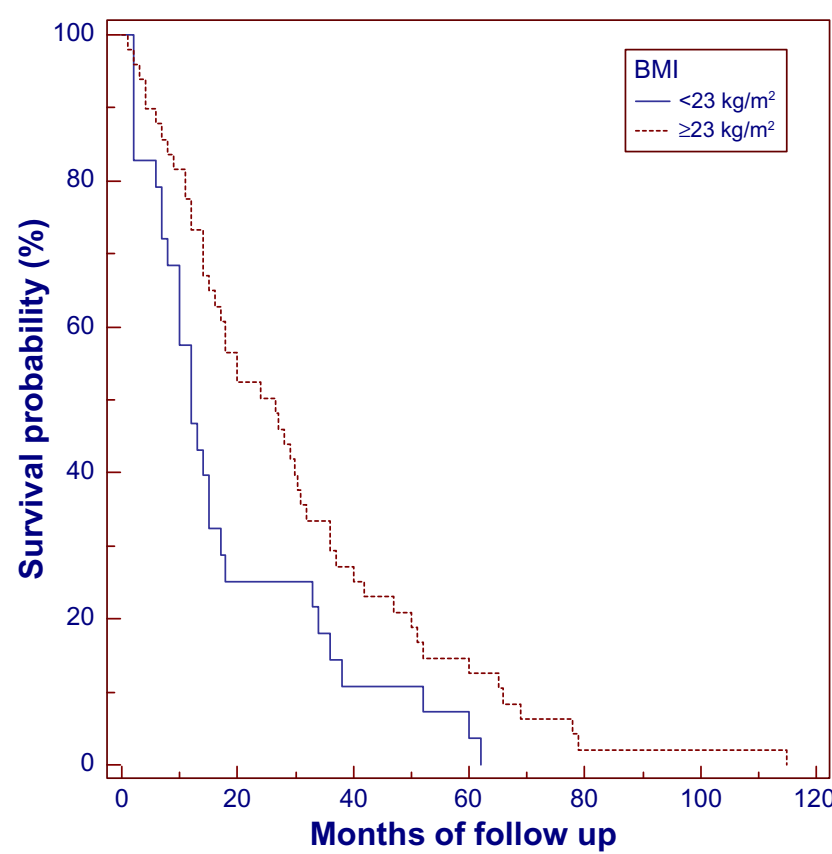

Figure 7 Kaplan-Meier survival curve for elderly hemodialysis patients, according to the BMI values.

Notes: $\mathrm{BMI}<23 \mathrm{~kg} / \mathrm{m}^{2}, \mathrm{n}=29 ; \mathrm{BMI} \geq 23 \mathrm{~kg} / \mathrm{m}^{2}, \mathrm{n}=49$. HR $\quad \mathrm{I.7022} ; 95 \%$ Cl: 1.0164-2.0508; $P<0.0001$.

Abbreviations: $\mathrm{BMI}$, body mass index; $\mathrm{Cl}$, confidence interval; $\mathrm{HR}$, hazard ratio. 


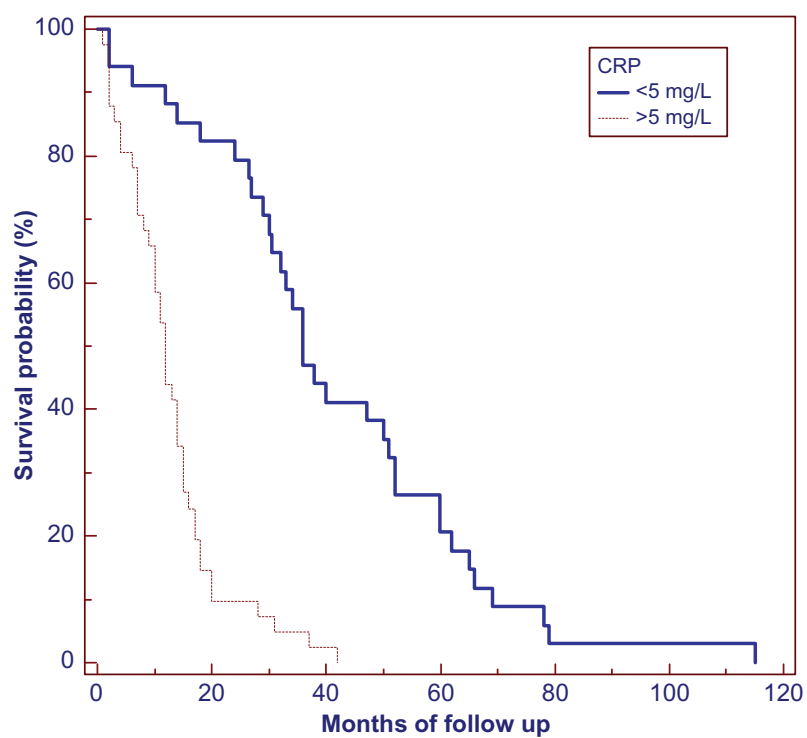

Figure 8 Kaplan-Meier survival curves for elderly hemodialysis patients, according to the CRP levels.

Notes: CRP $<5$ mg/L, n=34; CRP $>5$ mg/L, $n=4 I$. HR 3.4040; 95\% Cl: 2.0340-5.6969; $P<0.000$ I.

Abbreviations: $\mathrm{Cl}$, confidence interval; CRP, C-reactive protein; $\mathrm{HR}$, hazard ratio.

decade, this phenomenon translated into higher health care costs and additional clinical challenges, for the physician, to meet the often broader and more demanding health care needs of the geriatric population..$^{10}$ When an elderly person, especially the very elderly ( $\geq 80$ years old), faces the possibility of HD, the nephrologist often has difficulty making treatment decisions and must consider many aspects regarding the patient's underlying condition and probable outcome. The quality of life in elderly patients with renal failure becomes a very relevant clinical problem in everyday clinical practice. Despite complex comorbid and psychosocial conditions, survival and the quality of life in elderly patients on HD are often acceptable. ${ }^{2-11}$ Authors have drawn varied conclusions, based upon the period of evaluation, type of patient, study design, and outcome measured. Some authors found significantly improved survival in older adult patients who initiated HD versus those treated conservatively. For example, Carson et $\mathrm{al}^{11}$ conducted a study of 202 elderly patients with ESRD, and they found higher median survival among those who underwent $\mathrm{HD}$ treatment versus patients treated conservatively (38 versus 14 months, respectively). On the other hand, others have shown that initiation of HD was associated with high mortality and a sustained decline in functional status in this population of patients. For example, Kurella et $\mathrm{al}^{5}$ showed a decreasing mean survival after HD initiation in the older HD population: 24.9 months in those aged 65-79 years, 15.6 months in those aged $80-84$ years, 11.6 months for those 85-89 years, and 8.4 months in those aged 90 years and older.
A

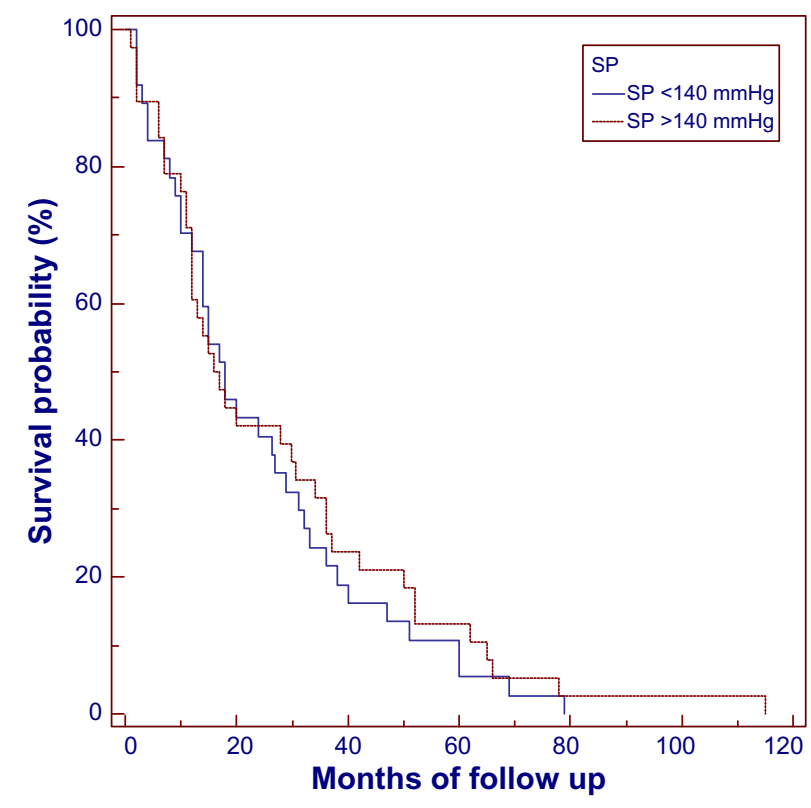

B

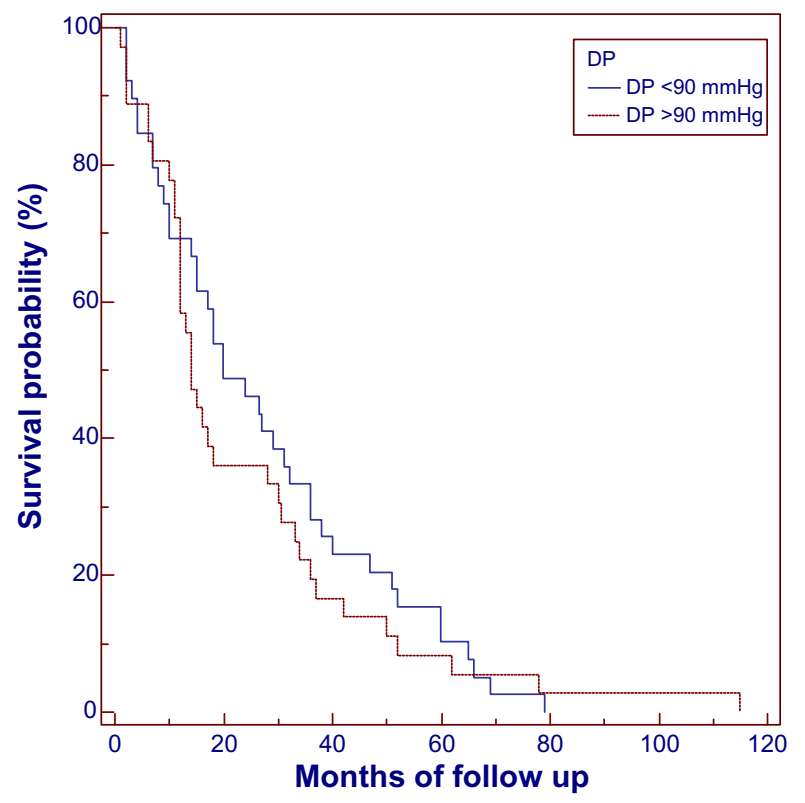

Figure 9 Kaplan-Meier survival curves for elderly hemodialysis patients, according to $(\mathbf{A})$ the $S P$ values and $(\mathbf{B})$ the DP values.

Notes: SP $<140 \mathrm{mmHg}, \mathrm{n}=37 ; \mathrm{SP}>140 \mathrm{mmHg}, \mathrm{n}=41$. DP $<90 \mathrm{mmHg}, \mathrm{n}=40$; $\mathrm{DP}>90 \mathrm{mmHg}, \mathrm{n}=38 . P=$ non-significant.

Abbreviations: DP, diastolic pressure; SP, systolic pressure.

Furthermore, according to the literature, life expectancy in patients that are $\geq 80$ years of age who initiate HD is $2-2.4$ years. ${ }^{2-6}$ In our study, almost one-third of patients that were $\geq 80$ years of age survived $12-24$ months; and one-third of them survived between 24-60 months.

However, advanced age is not the only predictive factor. And in the present study, as might be expected, the 


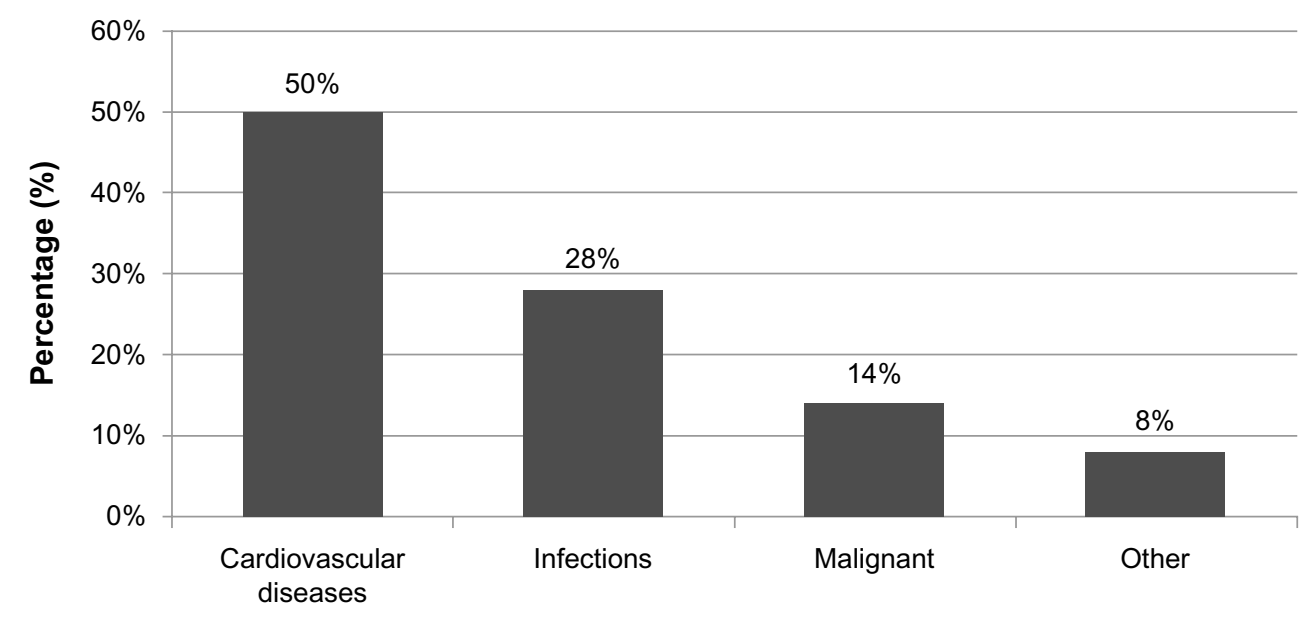

Figure 10 Causes of death in analyzed group of patients.

independent predictors of increased mortality were: absence of pre-HD care, catheter as vascular access for HD, poor nutritional status, and high CRP values.

Our patients with CKD stage 5 who were $\geq 80$ years who were referred to our nephrology care early and who followed a planned HD pathway had a survival advantage. For our patients who chose HD in pre-HD nephrology care, we do not know how much of the survival benefit was due to the treatment itself and how much reflects bias introduced by the selection process itself. Those patients attending pre-HD nephrology care and starting HD management might have been more likely to survive because of better physical status, less comorbid disease, or other unknown factors. The retrospective nature of our study did not allow us to analyze indicators of physical status, but we are planning to analyze this in future, prospective work. These results are similar to those of some other studies..$^{2-7,12-14}$ Furthermore, it is well known that catheter use has been associated with an increased mortality risk in HD patients. Ocak et a ${ }^{15}$ showed that this is especially important in elderly HD patients. In their study, patients with a catheter had an increased all-cause, infection-related, and cardiovascular mortality risk as compared with patients having an arteriovenous access. Our results are similar to those, indicating that the use of catheters for HD should be discouraged. This is especially important in very elderly patients because older age and catheter use are associated with an even higher increased mortality risk. According to the literature, mortality is also higher in patients with a graft compared with patients with a native fistula. ${ }^{16,17}$ In our study, none of our patients had a graft. Therefore, for very old patients ( $\geq 80$ years of age), we believe that arteriovenous fistula should be the first choice for chronic HD access, in appropriately selected patients who are thought to have a reasonably good chance of fistula maturation prior to initiation of HD. ${ }^{15}$ In patients with ESRD, especially those on $\mathrm{HD}$, it is important to maintain a good nutritional status before starting HD treatment. According to the literature, malnutrition was consistently observed among elderly patients across many studies. ${ }^{18}$ In our analysis, patients with good nutritional status had a significantly better survival compared with those with low BMI and serum albumin levels. Also, low serum albumin levels were an independent predictor of mortality. These findings suggest that two major mortality risk factors, poor nutritional status and hypoalbuminemia, are common among elderly HD patients and require specific attention, thus emphasizing the importance of optimizing nutrition in our pre-HD CKD population. These observations are in accordance with the current guidelines about adequate nutritional care for ESRD patients. ${ }^{19}$ Also, as we expected, patients with high CRP levels had worse survival.

The causes of ESRD tend to be similar in all age groups. But, according to the literature, elderly patients are less likely than younger patients to have ESRD secondary to diabetes or glomerulonephritis, and are more likely to have renal vascular disease and/or hypertension. Although diabetes continues to be the most common cause of ESRD in older patients, the relative proportion of those starting RRT because of diabetes compared with other causes is lower than in younger persons. ${ }^{20}$ The results of our study are in accordance with these observations. Namely, in our study, older patients were less likely to have diabetes, and primary renal disease had no influence on survival. This is partly because those patients with complications of diabetes probably died early.

Although there seems to be no sex-related difference in acceptance or referral of elderly patients for HD, there is a predominance of males among elderly HD patients, as was also shown in our study. In contrast with Chandna et $\mathrm{al}^{21}$ who showed 
a better survival in old women, in our analysis, there were no statistically significant difference in survival due to sex.

Our study had some limitations. The first was the retrospective design of the study and the absence of detail on patient characteristics, such as Karnofsky performance score and frailty. The second limitation was our relatively small number of patients. And third, we did not have a group of very old patients with ESRD who were treated conservatively. But the study shows a few important things. It demonstrated an increasing incidence of very old ESRD patients who were managed with HD during the last few years. Survival of very old patients treated with HD is variable, depending on the center, country, and registry, and the results of our study indicate that elderly patients can survive for long periods of time. It is important to note that advanced age is not the only predictive factor. However, survival is influenced strongly by some important factors, such as vascular access, nutritional status, and pre-HD nephrology care, as well as cardiac disease. Once these are taken into account, the age of elderly patients is not an independent risk factor for increased mortality in some models. ${ }^{14}$ This is consistent with the fact that the characteristics of an individual patient are more important than numerical age. HD should therefore not be denied to patients on the basis of age alone, if it is otherwise appropriate and if there is hope for prolongation of an enjoyable span of life.

\section{Disclosure}

The authors report no conflicts of interest in this work.

\section{References}

1. Orimo H, Ito H, Suzuki T, Araki A, Hosoi T, Sawabe M. Reviewing the definition of "elderly". Geriatrics \& Gerontology International. 2006;6(3):149-158.

2. Murtagh FE, Marsh JE, Donohoe P, Ekbal NJ, Sheerin NS, Harris FE. Dialysis or not? A comparative survival study of patients over 75 years with chronic kidney disease stage 5. Nephrol Dial Transplant. 2007;22(7):1955-1962.

3. Glaudet F, Hottelart C, Allard J, et al. The clinical status and survival in elderly dialysis: example of the oldest region of France. BMC Nephrol. 2013;14(1):131.

4. Coresh J, Astor BC, Greene T, Eknoyan G, Levey AS. Prevalence of chronic kidney disease and decreased kidney function in the adult US population: Third National Health and Nutrition Examination Survey. Am J Kidney Dis. 2003;41(1):1-12.
5. Kurella M, Covinsky KE, Collins AJ, Chertow GM. Octogenarians and nonagenarians starting dialysis in the United States. Ann Intern Med. 2007;146(3):177-183.

6. Stel VS, van de Luijtgaarden MW, Wanner C, Jager KJ; European Renal Registry Investigators. The 2008 ERA-EDTA Registry Annual Report-a précis. NDT Plus. 2011;4(1):1-13.

7. Jager KJ, van Dijk PC, Dekker FW, Stengel B, Simpson K, Briggs JD; ERA-EDTA Registry Committee. The epidemic of aging in renal replacement therapy: an update on elderly patients and their outcomes. Clin Nephrol. 2003;60(5):352-360.

8. Couchoud C, Lassalle M, Stengel B, Jacquelinet C. [Renal epidemiology and information network: 2009 annual report]. Nephrol Ther. 2011;7(Suppl 2):S41-S214. French.

9. Foote C, Ninomiya T, Gallagher M, et al. Survival of elderly dialysis patients is predicted by both patient and practice characteristics. Nephrol Dial Transplant. 2012;27(9):3581-3587.

10. Canaud B, Tong L, Tentori F, et al. Clinical practices and outcomes in elderly hemodialysis patients: results from the Dialysis Outcomes and Practice Patterns Study (DOPPS). Clin J Am Soc Nephrol. 2011;6(7): 1651-1662.

11. Carson RC, Juszczak M, Davenport A, Burns A. Is maximum conservative management an equivalent treatment option to dialysis for elderly patients with significant comorbid disease? Clin J Am Soc Nephrol. 2009;4(10):1611-1619.

12. McDonald S, McCredie M, Williams S, Stewart J. Factors influencing reported rates of treated end-stage renal disease. Adv Chronic Kidney Dis. 2005;12(1):32-38.

13. Hsu CY, Vittinghoff E, Lin F, Shlipak MG. The incidence of end-stage renal disease is increasing faster than the prevalence of chronic renal insufficiency. Ann Intern Med. 2004;141(2):95-101.

14. Winkelmayer WC, Tamura MK. Predialysis nephrology care of older individuals approaching end-stage renal disease. Semin Dialysis. 2012;25:628-632.

15. Ocak G, Halbesma N, le Cessie S, et al. Haemodialysis catheters increase mortality as compared to arteriovenous accesses especially in elderly patients. Nephrol Dial Transplant. 2011;26(8):2611-2617.

16. Hemodialysis Adequacy 2006 Work Group Membership. NFK-KDOQI clinical practice guidelines for hemodialysis adequacy, update 2006. Am J kidney Dis. 2006;48(Suppl 1):S2-S90.

17. Tordoir J, Canaud B, Haage P, et al. EBPG on vascular access. Nephrol Dial Transplant. 2007;22 Suppl 2:ii88-ii117.

18. Schmieder RE, Mann JF, Schumacher H, et al; ONTARGET Investigators. Changes in albuminuria predict mortality and morbidity in patients with vascular disease. J Am Soc Nephrol. 2011;22(7): 1353-1364.

19. National Kidney Foundation. KDOQI clinical practice guidelines for nutrition in chronic renal failure. Am J Kidney Dis. 2000;35(Suppl 2): S66-S70.

20. Krishnan M, Lok CE, Jassal SV. Epidemiology and demographic aspects of treated end-stage renal disease in the elderly. Semin Dial. 2002;15(2):79-83.

21. Chandna SM, Da Silva-Gane M, Marshall C, Warwicker P, Greenwood RN, Farrington K. Survival of elderly patients with stage 5 CKD: comparison of conservative management and renal replacement therapy. Nephrol Dial Transplant. 2011;26(5):1608-1614.
Clinical Interventions in Aging

\section{Publish your work in this journal}

Clinical Interventions in Aging is an international, peer-reviewed journal focusing on evidence-based reports on the value or lack thereof of treatments intended to prevent or delay the onset of maladaptive correlates of aging in human beings. This journal is indexed on PubMed Central, MedLine, the American Chemical Society's 'Chemical Abstracts

\section{Dovepress}

Service' (CAS), Scopus and the Elsevier Bibliographic databases. The manuscript management system is completely online and includes a very quick and fair peer-review system, which is all easy to use. Visit $\mathrm{http}: / / \mathrm{www}$.dovepress.com/testimonials.php to read real quotes from published authors. 